\title{
An Innovative Design Methodology KKBDCA for Affective Product Development
}

\author{
Kun-Chieh Wang ${ }^{1}$ and Fang-Rong Ju' ${ }^{2}$ \\ ${ }^{1}$ Department of Computer-Aided Industrial Design, Overseas Chinese University, Taichung, Taiwan \\ ${ }^{2}$ Institute of Technological Product Design, Ling Tung University, Taichung, Taiwan \\ Correspondence should be addressed to Kun-Chieh Wang; simpleyoung0104@gmail.com
}

Received 15 September 2013; Accepted 13 October 2013

Academic Editor: Teen-Hang Meen

Copyright (C) 2013 K.-C. Wang and F.-R. Ju. This is an open access article distributed under the Creative Commons Attribution License, which permits unrestricted use, distribution, and reproduction in any medium, provided the original work is properly cited.

This study proposes an innovative design scheme, called KKBDCA (Kano model, Kansei engineering, Base information, Design developing, Creativity thinking, and quality Assurance) for developing affective products. Firstly, a modified Kano model is proposed to link the customer's overall satisfaction and customer's partial preferences. Secondly, the KE together with appropriate quantification theory is used to establish the mapping relationship between design elements and customers' preferences. Then, a prototype of product with high customer satisfaction index (CSI) is selected from the product database as design reference. Thirdly, through the operation of BDCA design procedure, a new style of product is performed. Finally, verification is done to the new designed product and a satisfying evaluation result is obtained. The proposed integrated scheme may be used as a design methodology to explore new product style that satisfies customers' needs in overall aspects.

\section{Introduction}

The factors that influence the willing of consumers to purchase a certain product are multiphases, such as psychologi$\mathrm{cal}$, economic, and social. These factors usually change with time and different customers have their own motivation to make purchase decision. Among these factors, there is one deterministic factor that never changes: the customers' preferences.

Customer's preference or sensation is hard to be expressed and even hard to quantify, and there were lots of ways proposed to express human's preference about a product, such as words, physiological response (e.g., heart rate, EMG, and EEG), people's behaviors and actions, and facial and body expressions $[1,2]$. Among these different ways of measuring human's affection or Kansei (Japanese word), the most common way is through words. This method has been successfully applied in many product design studies [3-8]. However, only one single word or even multiple words are not sufficient to describe customer's preference. Moreover, improper consideration of the Kansei words may lead to vital results when designing products matching customers' requirements.
In general, the purchase decision of a customer is directly controlled by his overall satisfaction about the product, not his partial preference. And, how much influence of the individual sensation on the overall satisfaction is still not clear.

To link the customer's overall satisfaction with individual sensation, a modified Kano's model is proposed by this study. Originally speaking, the Kano model [9] is a 2D diagram in order to display three groups of qualitative wants and needs of customers. These three groups include basic needs, performance needs, and motivational needs as shown in Figure 1. The basic needs curve (must-be requirement) of Kano model shows that if customers expect more satisfaction with receiving products and services, it cannot satisfy customers. The excitement needs curve (one-dimensional requirement) shows that whenever the product has a higher performance, customers receive more satisfaction. The performance needs curve (attractive requirement) indicates the fact that nonfulfillment of performance requirements in the product will cause dissatisfaction, but complete and suitable fulfillment of them will be followed by customers' satisfaction.

The next problem is how to convert the customers' preferences into product design elements and eventually design 


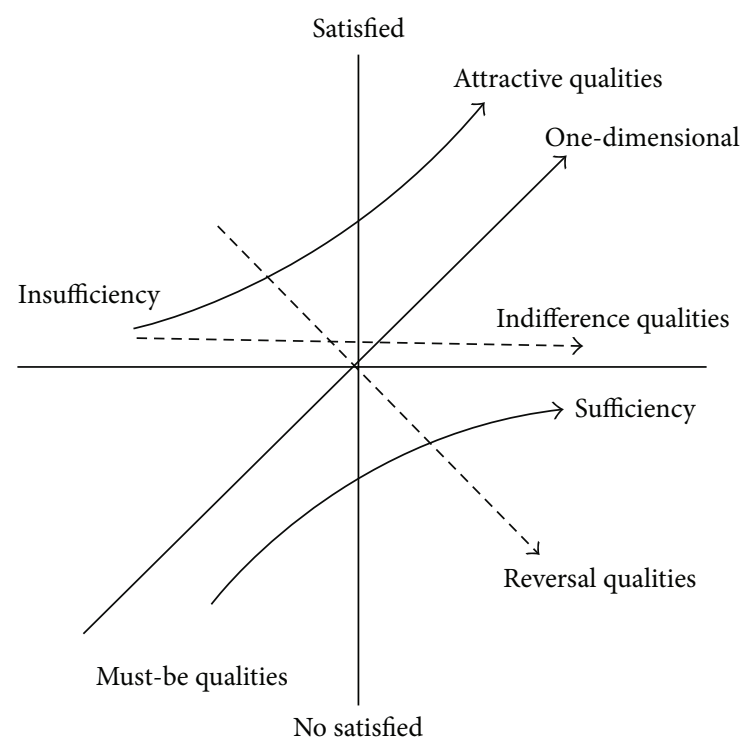

FIgUre 1: The Kano model.

an innovative product satisfying customers. To concretely translate the customer preference into product design elements, many methodologies were proposed in the past, such as quality function development (QFD) and matrix approach $[10,11]$. Specifically, a popular methodology to translate consumers' psychological feelings about a product into perceptual design elements is the "Kansei Engineering" (KE) [1,2]. It uses the "adjective words (Kansei words)" to describe the human preference and builds proper model to map these words into product design elements. Based on this mapping model, designers may easily evaluate product design style and design suitable product style meeting the given Kansei words. The Kansei engineering has been successfully applied in the field of product design $[9,12-14]$ to explore the relationship between the feeling of the consumers and the design elements of the product. Examining these studies, it is found that they did not extend the Kansei engineering scheme to really design a product and evaluate the design results from the viewpoint of customer satisfaction. In other words, the application of Kansei engineering scheme was so far limited and only used for evaluating the customer preference to existed products. Regarding this, this study attempts to develop an innovative design procedure, named BDCA, to compensate the insufficiency of KE.

In summary, our study will not only include the traditional Kansei engineering procedure to build a suitable model to connect the design features with customer preference (Kansei words) but also extend both upstream to include customer satisfaction (using the modified Kano model) and downstream to include the innovation procedure of product design. Furthermore, an overall customer satisfaction index is proposed to objectively evaluate the new design results from the viewpoint of customer preference. The manipulation procedures (Step 1 to Step 8) are shown in Figure 2 and explained as follows. (1) Firstly, we propose a modified Kano model to link the customer Kansei with customer satisfaction (Step 1 to Step 4). (2) Secondly, the Kansei engineering scheme

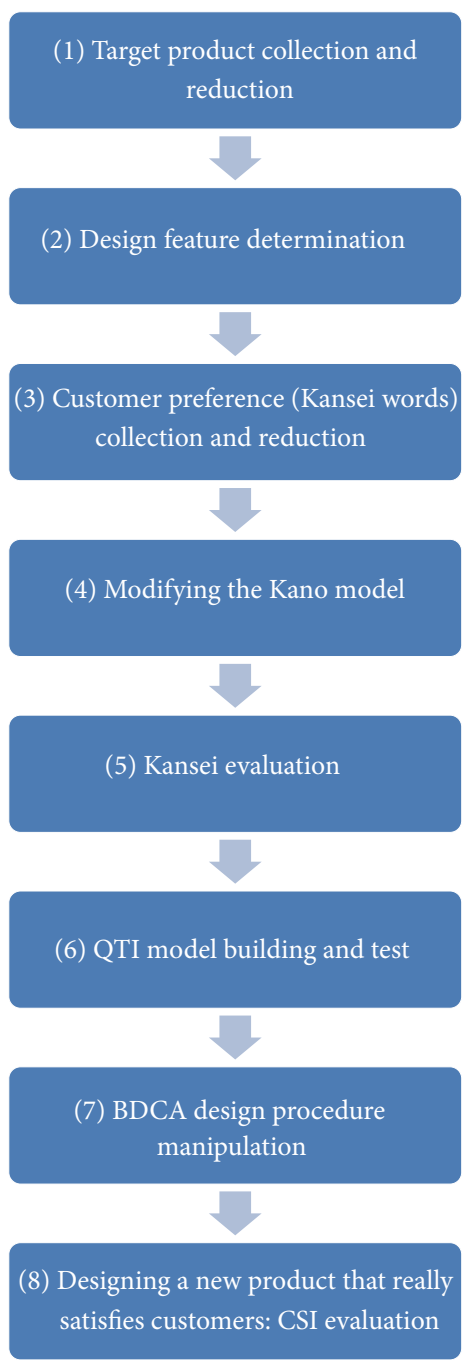

FIGURE 2: The KKBDCA innovative product design procedure based on customer satisfaction.

together with the QT I is used to map the design elements into customer Kansei (Steps 5 and 6). (3) Thirdly, using the highweighting design elements as basis, an illustrative new style of digital camera is thus designed. (4) Then, the BDCA design procedure is introduced to design a new product (Step 7). (5) Eventually, a customer satisfaction index (CSI) is proposed to give a final evaluation on judging the goodness of the new designed product (Step 8).

\section{Methodology}

2.1. The Modified Kano Model. In order to link the customers' partial preferences with their overall satisfaction about a product, the aforementioned Kano's model is modified as follows. First, the above three categories of customer needs remain unchanged. Second, the horizontal axis is modified from "manner of product and service" into "customer's Kansei about products (adjective words)." This modification establishes a bridge between customer's individual Kansei and customer's overall satisfaction. Through this modified 
Kano model, designers may easily understand what category the customer preference belongs to and how much influence it has on the customer satisfaction.

2.2. The Kansei Engineering. According to Nagamachi [2], there are six types of KE technique categorized as follows: (1) Type I: category classification, (2) Type II: Kansei engineering system, (3) Type III: Kansei engineering modeling, (4) Type IV: hybrid Kansei engineering, (5) Type V: virtual Kansei engineering, and (6) Type VI: collaborative Kansei engineering. In this study, we are focusing on Type III. The major work of the KE modeling (TYPE III) is to establish a proper model that connects people's psychological feelings with perceptual design elements of a product. Meanwhile, to complete the KE modeling work, the popular Quantitative Theory Type I [15] is used to build the relationship of product design elements and Kansei words. The entire manipulation procedure, including five steps, is described as follows.

Step 1. Initially, products within a specifically domain are described from two perspectives: a semantic perspective (image space) and a physical perspective (design space). These two descriptions span one space each, which in some cases can be defined mathematically as a vector space [16].

Step 2. Data in these two spaces are analyzed and reduced using statistical methods [17] such as K-Means method (KM), Kawakita Jirol method (KJ), multi-dimensional scaling method (MDS), hierarchical cluster analysis (HCA), and factor analysis (FA).

Step 3. Subsequently, the interactions between these two spaces are analyzed to realize their behavior. A final Kansei evaluation of questionnaire survey (product feature elements versus product images) is accomplished by proper subjects.

Step 4. Then the QT1 is applied to establish the relationship between product feature elements and product images. The weightings of every design attribute on different Kansei words are examined as the modification basis for designing future product.

Step 5. To evaluate the performance of our proposed integrated schemes, a validity test for the modeling is conducted.

2.3. The Quantification Mapping Model. The Quantitative Theory Type I is a multiple regression analysis scheme for deducing the relationship between a quantitative variable and qualitative variables. Here the quantitative variable, also the dependent variable, is set as the Kansei word, and the qualitative variables, also the independent variables, are set as design parameters. The mapping results are expressed in terms of the partial correlation coefficients (PCCs). The value of PCC indicates the relative importance of each design parameter to each Kansei word. Furthermore, the correlation between the observed value and predicted value of the dependent variables, expressed as $R$, is calculated. The coefficient of multiple determinations is $R^{2}$. This parameter explains the linearity

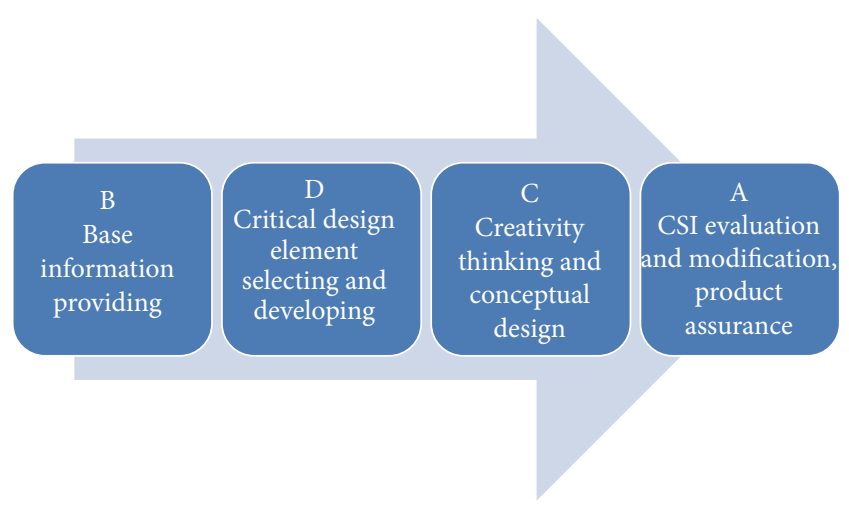

FIgURE 3: The BDCA design procedure.

extent between the dependent variables and independent variable.

2.4. The BDCA Design Procedure. This study proposes a design procedure, called KKBDCA, to design a product based on the results obtained from the Kano model and the Kansei engineering. The remained BDCA means base information, design developing, creativity thinking, quality assurance, as shown in Figure 3. This procedure includes four steps. Firstly, we select the highest CSI value sample as the design reference. Then, we examine the variation influence of all design elements on each Kansei word and think about their relationship. Secondly, we extract the commonly high influential elements of each of design categories for all three qualitysufficiency Kansei words, according to the results from the modified Kano model and Kansei engineering manipulation. Thirdly, we execute the creativity thinking work and perform the conceptual design. Fourthly, we introduce the questionnaire survey to the obtained prototype and calculate its CSI value. Then, we modify the prototype to obtain a new model of product which may catch current customers' overall satisfaction.

\section{Results and Discussion}

Here we choose the digital camera as the experimental target, but the proposed methodologies can be applied to other similar products with various design elements. The experimental study involves 30 subjects. Each has more than 3 years of experience in using digital camera. The following is the manipulation processes of the customer-satisfaction-based KE technique applying to the innovative design of a digital camera.

\subsection{Product Information}

3.1.1. Sample Collection. To identify the design elements of digital cameras, we first selected 159 digital cameras of various makers and models, which entered the market during 20062011. Totally 60 styles of digital cameras, excluding those using for specific purposes or styles with too exaggerated outlooking, were chosen to represent the space of product. These 
samples were represented in pictures that had been done as similar as possible in contrasts, sizes, and soon to be comparable in the experiment. The pictures were also of good quality and shading to represent the three dimensional shapes of the products. We then asked the subjects to classify these 60 digital camera samples into 2 10 groups based on their similarity degree, using Kawakida Jirou method. This method was introduced by Kawakida Jirou in 1953 [18] for classifying ideas, concepts, or objects into several groups by their similarity degree. All participants were skilled in visualization and capable of considering three-dimensional shapes from pictures. Then, we built a similarity matrix from the previously obtained separation result. The similarity matrix was transformed into a dissimilarity matrix and analyzed by the multidimensional scaling (MDS) scheme. To determine the most appropriate dimensionality for the data, we examined 9 different dimensional spaces (ranging from 2 to 10 dimensions). A result of 6-dimensions with stress of 0.04912 was suggested here, since a commonly used measure of fit in MDS is "stress", which is the square root of a normalized residual sum of squares. A smaller stress value indicates a better fit (an empirical suggested stress value is 0.05 [17]). Thus, the 6 dimensional spaces were appropriate. Finally, the hierarchical cluster analysis (HCA) was performed based on the MDS result.

Furthermore, the representative of each group was obtained via the K-means clustering scheme. This scheme calculates the distance of individual sample to its group center of gravity and eventually the sample which has the smallest distance can be visualized as the group representative. For instance, the samples and their representative of group 2, including the calculated distances to their group center of gravity, are obtained and shown in Table 1.

3.1.2. Product Feature. Distinguished from the usual way that only considered the form style as the design parameter, this study, more meaningfully, extends the design elements to include three design categories: hardware appearance design, form style, and color type. Regarding this, a detailed design analysis, including the morphological analysis, is performed to extract the design features from the 6 representatives and their group samples. The result is listed in Table 2 which shows the obtained 3 categories of design features and 11 associated design elements (denoted as X1 X11). Each design element has its own different variation, numbering from 1 to 4.

3.2. Product Image. This study uses the Kansei words (image words) to describe the consumer's psychological feeling and perception about the image of a product. The following is the details to extract the representatives of image words.

3.2.1. Image Collection. A total of 60 Kansei adjective words describing the integral feeling of collected digital cameras were chosen from magazines, literature, manuals, experts, experienced users and product catalogs. And after deleting those too exaggerated, similar, or overlapping words, eventually a total of 24 low-level Kansei words was built up.
TABLE 1: The sample classification results: samples of Group 2 and their representative.

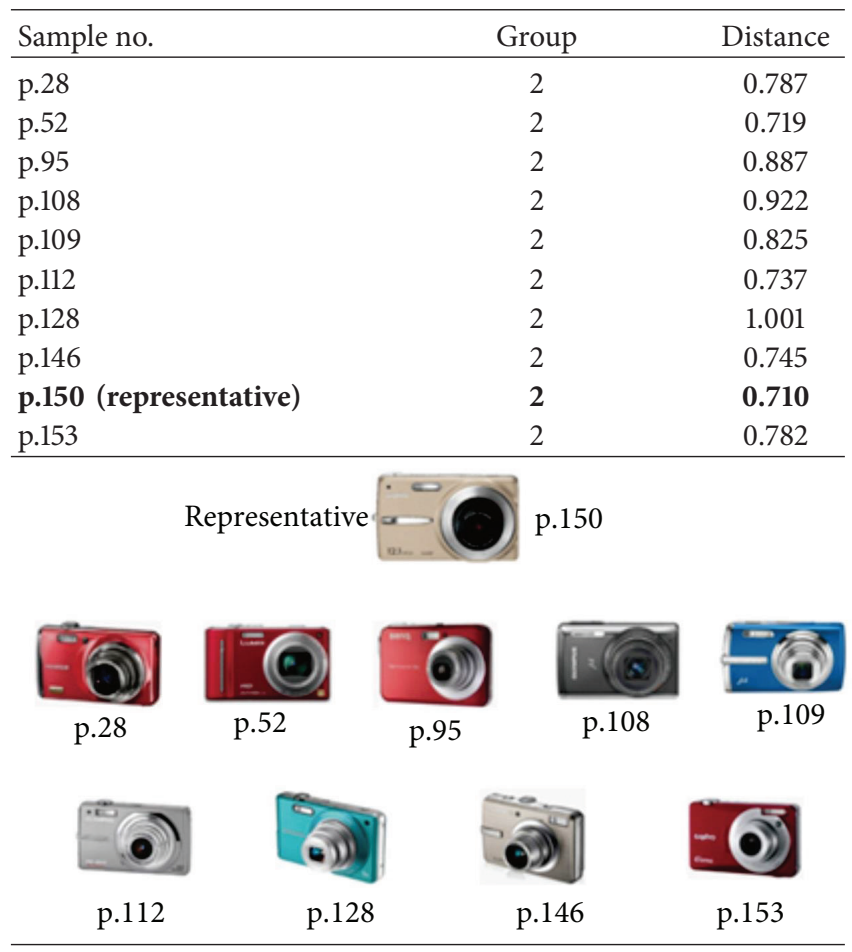

p.: product.

Bold font means the data of representative of Group 2.

3.2.2. High-Level Kansei Words. To extract the representative image words for describing the consumers' perception about the collected digital cameras, a designed questionnaire interview was done to the subjects. A result of three final high-voted high-level Kansei words of product images was obtained as follows: usability $\left(Y_{1}\right)$, aesthetics $\left(Y_{2}\right)$, and innovation $\left(Y_{3}\right)$.

3.3. Quality Sufficiency of Image. Based on the proposed modified Kano model, (1) the vertical axis is set as the overall customer satisfaction about a product and denoted as CSI and (2) the horizontal axis is set as the quality-sufficiency highlevel Kansei words, denoted as $Y_{1} \sim Y_{3}$, which represent the proper feelings (preferences) of consumers about the selected products. To determine the contribution extent as well as classification of each quality-sufficiency Kansei word to the overall customer satisfaction, a questionnaire survey was done to 30 subjects. The major question is how much influence will happen (range: $-5 \sim 5$ ) if the extent of Kansei word is increased by one unit. The obtained mean influence weighting of $Y_{1}$, $Y_{2}$, and $Y_{3}$ on customer satisfaction is $W_{1}=1.3, W_{2}=0.47$, and $W_{3}=1.16$ and it can be classified as attractive, one-dimensional, and one-dimensional quality, respectively (shown in Table 3 ).

\subsection{Mathematic Mapping Model}

3.4.1. Sample Evaluation. The Kansei evaluation questionnaire is done to 30 subjects for evaluating their preference 
TABle 2: Design feature decomposition.

\begin{tabular}{|c|c|c|c|c|c|}
\hline Design attribute & $\begin{array}{c}\text { Design } \\
\text { element }\end{array}$ & Type I & Type II & Type III & Type IV \\
\hline \multirow{8}{*}{ Hardware design } & Power (X1) key & Pushing-on type (X11) & Turning-on type (X12) & Sliding-on type (X13) & \\
\hline & $\begin{array}{l}\text { Picturing switch button } \\
\text { (X2) }\end{array}$ & Wheel (X21) & $\begin{array}{c}\text { Touch } \\
\text { screen }(\mathrm{X} 22)\end{array}$ & $\begin{array}{l}\text { Combined with the } \\
\text { function key (X23) }\end{array}$ & \\
\hline & & $\mathrm{X} 31$ & $\mathrm{X} 32$ & X33 & $\mathrm{X} 34$ \\
\hline & $\begin{array}{c}\text { Function } \\
\text { Key type (X3) }\end{array}$ & & $\Gamma_{0}$ & & \\
\hline & & & $\square$ & 西 & \\
\hline & Screen size $(\mathrm{X} 4)$ & $3.5^{\prime \prime}(\mathrm{X} 41)$ & $3^{\prime \prime}(\mathrm{X} 42)$ & $2.7^{\prime \prime}(\mathrm{X} 43)$ & $2.5^{\prime \prime}(\mathrm{X} 44)$ \\
\hline & & X51 & X52 & & \\
\hline & Len type (X5) & & $\square$ & & \\
\hline \multirow{5}{*}{ Form style } & Upper face (X6) & X61 & X62 & X63 & $\mathrm{X} 64$ \\
\hline & & $\mathrm{X} 71$ & $\mathrm{X} 72$ & $\mathrm{X} 73$ & $\mathrm{X} 74$ \\
\hline & Front face (X7) & & & & \\
\hline & & $\mathrm{X} 81$ & $\mathrm{X} 82$ & & \\
\hline & Side face (X8) & & 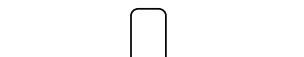 & & \\
\hline \multirow{3}{*}{ Color type } & Front face: brightness (X9) & $\begin{array}{l}\text { No } \\
(\mathrm{X} 91)\end{array}$ & $\begin{array}{l}\text { Low } \\
(\mathrm{X} 92)\end{array}$ & $\begin{array}{l}\text { Medium } \\
\text { (X93) }\end{array}$ & $\begin{array}{l}\text { High } \\
(\mathrm{X} 94)\end{array}$ \\
\hline & $\begin{array}{l}\text { Front face: } \\
\text { hue (X10) }\end{array}$ & $\begin{array}{c}\text { No } \\
(\mathrm{X} 101)\end{array}$ & $\begin{array}{l}\text { Low } \\
\text { (X102) }\end{array}$ & $\begin{array}{l}\text { Medium } \\
(\mathrm{X} 103)\end{array}$ & $\begin{array}{l}\text { High } \\
\text { (X104) }\end{array}$ \\
\hline & $\begin{array}{l}\text { Rear face: } \\
\text { color (X11) }\end{array}$ & $\begin{array}{l}\text { Same with front face } \\
\text { (X111) }\end{array}$ & $\begin{array}{l}\text { Black } \\
(\mathrm{X} 112)\end{array}$ & $\begin{array}{l}\text { Silver } \\
\text { (X113) }\end{array}$ & \\
\hline
\end{tabular}

TABLE 3: The relationship between customer satisfaction and customer preference.

\begin{tabular}{lccc}
\hline $\begin{array}{l}\text { Quality- } \\
\text { sufficiency } \\
\text { image }\end{array}$ & $Y_{1}$ (usability) & $Y_{2}$ (aesthetics) & $Y_{3}$ (innovation) \\
\hline $\begin{array}{l}\text { Influence on } \\
\begin{array}{l}\text { CSI } \\
\text { (weighting) }\end{array}\end{array}$ & $W_{1}=1.3$ & $W_{2}=0.47$ & $W_{3}=1.16$ \\
\hline $\begin{array}{l}\text { Kano } \\
\text { category }\end{array}$ & $\begin{array}{c}\text { Attractive } \\
\text { quality }\end{array}$ & $\begin{array}{c}\text { One- } \\
\text { dimensional } \\
\text { quality }\end{array}$ & $\begin{array}{c}\text { One- } \\
\text { dimensional } \\
\text { quality }\end{array}$ \\
\hline
\end{tabular}

about the collected 60 samples using the 7-scale semantic differential scheme. The obtained average score of $Y_{1} \sim Y_{3}$ is listed in Table 4. Further, the CSI value of each sample is calculated from the formula CSI $=\sum_{i=1}^{3} W_{i} Y_{i}$, and it is found that the N15 sample has the highest rank of customer satisfaction. This sample may be used as the basis of conceptual design so as to further design an innovative product.

3.4.2. Model Building. Based on the results of sample feature decomposition, together with the obtained Kansei credits of every sample listed in Table 4, the linear relationship between design elements and Kansei words can be built via QT1. The obtained results of the partial correlation coefficients (PCCs), which mean the relative importance of every design element on the Kansei image, are listed in Table 5.

(i) For $Y_{1}$ (usability).

It is seen that there is no influence on $Y_{1}$ for design parameters X12, X23, X31, X42, X51, X62, X71, X93, X104, and X111, since their PCCs are all zero. Further, $\mathrm{X} 32, \mathrm{X} 33, \mathrm{X} 34, \mathrm{X} 81$, and X82 have relatively high positive influences on $Y_{1}$ (the higher the better), since their coefficients are all greater than 0.3. On the other hand, X13, X21, and X52 have significantly reverse influences on $Y_{1}$ (the lower the better), since their coefficients are all smaller than -0.3 .

(ii) For $Y_{2}$ (aesthetics).

Design parameters X12, X23, X31, X42, X51, X62, X72, X93, X104, and X111 have no influence (zero PCC) on $Y_{2}$. High positive weighting (greater than 0.3 ) are found in design parameters: X33, X34, X81, X82, X102, $\mathrm{X} 112$, and $\mathrm{X} 113$. It is noted that the design parameters $\mathrm{X} 33, \mathrm{X} 34, \mathrm{X} 81$, and $\mathrm{X} 82$ have commonly positive influences on both $Y_{1}$ and $Y_{2}$. High reverse weighting (smaller than -0.3 ) is found in design parameters: $\mathrm{X} 13, \mathrm{X} 21, \mathrm{X} 22$, X44, X63, and X74. 
TABLE 4: The Kansei evaluation result (mean value) of all samples.

\begin{tabular}{|c|c|c|c|c|c|}
\hline Samples & $Y_{1}$ & $Y_{2}$ & $Y_{3}$ & CSI & Rank \\
\hline N01 & 4.35 & 4.17 & 3.79 & 12.011 & 35 \\
\hline N02 & 4.44 & 3.52 & 3.46 & 12.416 & 25 \\
\hline N03 & 3.68 & 3.52 & 3.46 & 10.452 & 58 \\
\hline N04 & 5.21 & 4.81 & 4.96 & 14.787 & 4 \\
\hline N05 & 4.90 & 4.31 & 4.43 & 13.535 & 15 \\
\hline N06 & 4.35 & 4.68 & 4.23 & 12.761 & 20 \\
\hline N07 & 4.33 & 4.55 & 3.87 & 12.257 & 31 \\
\hline N08 & 4.60 & 4.35 & 4.80 & 13.593 & 13 \\
\hline N09 & 4.91 & 4.34 & 4.57 & 13.724 & 11 \\
\hline N10 & 4.30 & 4.42 & 4.06 & 12.377 & 27 \\
\hline N11 & 3.38 & 3.34 & 2.99 & 9.432 & 60 \\
\hline N12 & 3.58 & 4.15 & 3.51 & 10.676 & 55 \\
\hline N13 & 5.07 & 4.50 & 4.34 & 13.740 & 10 \\
\hline N14 & 4.98 & 4.68 & 4.82 & 14.265 & 8 \\
\hline N15 & 4.98 & 4.94 & 5.65 & 15.350 & 1 \\
\hline N16 & 3.66 & 4.19 & 3.44 & 10.718 & 54 \\
\hline N17 & 4.39 & 3.58 & 3.37 & 11.299 & 45 \\
\hline N18 & 3.74 & 3.80 & 3.79 & 11.044 & 50 \\
\hline N19 & 5.60 & 4.94 & 4.02 & 14.265 & 7 \\
\hline $\mathrm{N} 20$ & 3.81 & 3.89 & 3.43 & 10.760 & 52 \\
\hline N21 & 4.51 & 4.44 & 3.36 & 11.847 & 38 \\
\hline $\mathrm{N} 22$ & 5.14 & 4.83 & 4.87 & 14.601 & 6 \\
\hline N23 & 5.25 & 5.35 & 4.78 & 14.884 & 3 \\
\hline N24 & 3.96 & 3.69 & 3.32 & 10.734 & 53 \\
\hline N25 & 5.07 & 4.33 & 4.27 & 13.579 & 14 \\
\hline N26 & 3.75 & 4.11 & 3.90 & 11.331 & 43 \\
\hline $\mathrm{N} 27$ & 3.94 & 4.15 & 3.62 & 11.272 & 46 \\
\hline N28 & 4.41 & 4.46 & 4.11 & 12.597 & 22 \\
\hline N29 & 4.20 & 3.46 & 2.92 & 10.473 & 57 \\
\hline N30 & 4.32 & 3.79 & 3.46 & 11.411 & 42 \\
\hline N31 & 4.91 & 3.89 & 3.44 & 12.202 & 33 \\
\hline N32 & 4.22 & 3.53 & 2.93 & 10.544 & 56 \\
\hline N33 & 4.67 & 4.04 & 3.78 & 12.355 & 29 \\
\hline N34 & 5.63 & 4.74 & 4.38 & 14.628 & 5 \\
\hline N35 & 4.63 & 3.88 & 3.78 & 12.227 & 32 \\
\hline N36 & 4.43 & 4.73 & 4.75 & 13.492 & 16 \\
\hline N37 & 4.43 & 3.70 & 3.39 & 11.430 & 41 \\
\hline N38 & 3.61 & 4.23 & 4.00 & 11.321 & 44 \\
\hline N39 & 3.57 & 4.11 & 4.05 & 11.271 & 47 \\
\hline $\mathrm{N} 40$ & 3.59 & 4.28 & 4.41 & 11.794 & 40 \\
\hline N41 & 3.81 & 3.27 & 3.26 & 10.272 & 59 \\
\hline $\mathrm{N} 42$ & 4.46 & 4.43 & 4.43 & 13.019 & 18 \\
\hline N43 & 4.19 & 4.34 & 4.95 & 13.229 & 17 \\
\hline N44 & 4.35 & 4.68 & 4.23 & 12.761 & 21 \\
\hline N45 & 4.45 & 4.66 & 3.85 & 12.441 & 24 \\
\hline N46 & 4.44 & 4.52 & 4.41 & 13.021 & 19 \\
\hline N47 & 3.99 & 4.34 & 4.46 & 12.400 & 26 \\
\hline N48 & 4.31 & 4.24 & 4.02 & 12.259 & 30 \\
\hline N49 & 4.39 & 4.11 & 3.61 & 11.826 & 39 \\
\hline N50 & 5.07 & 4.54 & 4.22 & 13.620 & 12 \\
\hline N51 & 3.74 & 4.21 & 3.75 & 11.191 & 48 \\
\hline
\end{tabular}

TABLE 4: Continued.

\begin{tabular}{lccccc}
\hline Samples & $Y_{1}$ & $Y_{2}$ & $Y_{3}$ & CSI & Rank \\
\hline N52 & 5.13 & 4.70 & 4.25 & 13.808 & 9 \\
N53 & 3.89 & 4.01 & 3.64 & 11.164 & 49 \\
N54 & 5.29 & 4.15 & 5.23 & 14.894 & 2 \\
N55 & 4.33 & 4.35 & 3.66 & 11.919 & 36 \\
N56 & 4.55 & 4.12 & 3.98 & 12.468 & 23 \\
N57 & 3.63 & 4.24 & 3.61 & 10.899 & 51 \\
N58 & 4.17 & 4.17 & 3.88 & 11.882 & 37 \\
N59 & 4.55 & 4.18 & 3.86 & 12.357 & 28 \\
N60 & 4.28 & 3.91 & 4.02 & 12.065 & 34 \\
\hline
\end{tabular}

(iii) For $Y_{3}$ (innovation).

Design parameters X12, X23, X31, X42, X51, X62, X71, $\mathrm{X} 93, \mathrm{X} 104$, and X111 have no influence (zero PCC) on $Y_{3}$. High positive weighting (greater than 0.3 ) is found in design parameters X11, X13, X32, X33, X34, X102, and $\mathrm{X} 112$. It is noted that the design parameters $\mathrm{X} 33$ and X34 have commonly and significantly positive influences on all three Kansei words. High reverse weighting (smaller than -0.3) is found in design parameters X21, X22, X61, X63, X73, X74, X81, and $\mathrm{X} 82$. It is noted that the design parameters $\mathrm{X} 21$, $\mathrm{X} 22$, X63, and X74 have commonly and significantly reverse influences on both $Y_{2}$ and $Y_{3}$.

3.4.3. Verification. To identify the modeling accuracy, other four samples (different from the 60 training samples), numbering T01, T02, T03, and T04, are randomly chosen from the sample population. These samples are decomposed first, and through questionnaire survey, the Kanei credits are obtained. Then the CSI value of each sample is calculated using the previously obtained Kano weighting for each quality-sufficiency Kansei word. The results including the final customer satisfaction ranking are listed in Table 6. It is found that although the predicted and experimental sample CSI values are slightly different, the ranking orders are the same. This result is obviously satisfying.

3.5. New Product Creation. Basically, the Kansei engineering is used to deal with customers' preference about products in the past. Also, the obtained design features of the target product are past events. Certainly, the current or future design of a product should be different from the past one. However, the KE modeling results do provide valuable design trace and may give us a guide for designing a future product. The following is the manipulation of the proposed BDCA design process to design an innovative future product based on the past-obtained KE results.

\subsubsection{The BDCA Procedure}

Step 1 (B-base information providing). Examining the PCCs of all design elements to three quality-sufficiency Kansei words, it is found that the most influential design factors for each design category are (1) X11 for category X1, 
TABLE 5: The QTI mapping result: relationship between Kansei words and design elements.

\begin{tabular}{|c|c|c|c|}
\hline Design elements & $Y_{1}$ & $Y_{2}$ & $Y_{3}$ \\
\hline \multicolumn{4}{|l|}{$\mathrm{X} 1$} \\
\hline X11 & -0.140 & 0.166 & 0.471 \\
\hline $\mathrm{X} 12$ & 0.000 & 0.000 & 0.000 \\
\hline X13 & -0.318 & -0.498 & 0.767 \\
\hline \multicolumn{4}{|l|}{$\mathrm{X} 2$} \\
\hline X21 & -0.710 & -0.417 & -0.395 \\
\hline $\mathrm{X} 22$ & 0.244 & -0.897 & -0.395 \\
\hline X23 & 0.000 & 0.000 & 0.000 \\
\hline \multicolumn{4}{|l|}{$\mathrm{X} 3$} \\
\hline X31 & 0.000 & 0.000 & 0.000 \\
\hline X32 & 0.346 & 0.249 & 0.323 \\
\hline X33 & 1.092 & 1.235 & 0.940 \\
\hline X34 & 1.071 & 1.622 & 0.380 \\
\hline \multicolumn{4}{|l|}{$\mathrm{X} 4$} \\
\hline $\mathrm{X} 41$ & -0.028 & -0.215 & -0.041 \\
\hline $\mathrm{X} 42$ & 0.000 & 0.000 & 0.000 \\
\hline $\mathrm{X} 43$ & 0.144 & -0.198 & -0.112 \\
\hline X44 & -0.027 & -0.565 & -0.137 \\
\hline \multicolumn{4}{|l|}{$\mathrm{X} 5$} \\
\hline X51 & 0.000 & 0.000 & 0.000 \\
\hline X52 & -0.353 & -0.130 & 0.158 \\
\hline \multicolumn{4}{|l|}{ X6 } \\
\hline X61 & 0.020 & -0.096 & -0.325 \\
\hline X62 & 0.000 & 0.000 & 0.000 \\
\hline X63 & 0.004 & -0.886 & -0.927 \\
\hline X64 & -0.223 & -0.281 & 0.213 \\
\hline \multicolumn{4}{|l|}{$\mathrm{X} 7$} \\
\hline X71 & 0.000 & 0.000 & 0.000 \\
\hline $\mathrm{X} 72$ & 0.109 & -0.145 & 0.061 \\
\hline X73 & -0.011 & 0.050 & -0.552 \\
\hline X74 & -0.147 & -0.554 & -0.345 \\
\hline \multicolumn{4}{|l|}{$\mathrm{X} 8$} \\
\hline X81 & 0.620 & 0.342 & -0.302 \\
\hline X82 & 0.580 & 0.483 & -0.582 \\
\hline \multicolumn{4}{|l|}{ X9 } \\
\hline X91 & 0.262 & 0.115 & 0.286 \\
\hline X92 & -0.049 & -0.254 & -0.174 \\
\hline X93 & 0.000 & 0.000 & 0.000 \\
\hline X94 & -0.087 & -0.009 & -0.231 \\
\hline \multicolumn{4}{|l|}{$\mathrm{X} 10$} \\
\hline X101 & -0.030 & -0.288 & -0.118 \\
\hline X102 & 0.138 & 0.331 & 0.332 \\
\hline X103 & -0.024 & 0.269 & 0.084 \\
\hline X104 & 0.000 & 0.000 & 0.000 \\
\hline
\end{tabular}

(2) X22 for category X2, (3) X33 and X34 for category X3,

(4) X44 for category X4, (5) X52 for category X5, (6) X63
TABLE 5: Continued.

\begin{tabular}{lccc}
\hline Design elements & $Y_{1}$ & $Y_{2}$ & $Y_{3}$ \\
\hline X11 & & & \\
$\quad$ X111 & 0.000 & 0.000 & 0.000 \\
X112 & -0.084 & 0.308 & 0.445 \\
$\quad$ X113 & -0.295 & 0.490 & 0.299 \\
$C$ (constant) & 3.814 & 3.884 & 3.972 \\
$R^{2}$ & 0.889 & 0.592 & 0.688 \\
\hline
\end{tabular}

TABLE 6: The CSI value and ranking of products from prediction and experiment.

\begin{tabular}{lcccc}
\hline & Sample T01 & Sample T02 & Sample T03 & Sample T04 \\
\hline Prediction & & & & \\
CSI & 12.259 & 13.558 & 13.450 & 10.812 \\
Ranking & 3 & 1 & 2 & 4 \\
\hline Experiment & & & & \\
$\quad$ CSI & 11.977 & 13.628 & 13.186 & 11.023 \\
Ranking & 3 & 1 & 2 & 4 \\
\hline
\end{tabular}

for category X6, (7) X73 for category X7, (8) X82 for category X8, (9) X91 for category X9, (10) X101 for category X10, and (11) X112 for category X11. These important design parameters give us a guide to design a good product satisfying customer needs. The enhancement of these design parameters may lead to an increase of CSI.

Further, it is crucial to offer an useful design reference in order to construct a new product prototype. Regarding this, this study proposes that the product having the highest CSI credit may be selected as a design reference, for example, the sample N15 (shown in Table 7). So far the preparation work before designing a prototype has been completed. The next step is to properly select design elements and creatively alter them.

Step 2 (D-critical design element selecting and developing). Based on the chosen high-score sample N15, we now change the type of design elements with zero or negative PCC and keep the other unchanged. It is noting that design elements with zero or negative PCC mean they have no or reverse influence on customer's preference. Therefore, they should be considered as the key design parameters to be changed first in order to create a new product style that can rapidly promote customers' preferences. Creative thinking can be actuated now from these key elements.

Step 3 (C-creativity thinking and conceptual design). After mature consideration, the creative alteration is done to the previously suggested key design elements. With the help of software SolidWorks, a conceptual design of new prototype is performed. The three-dimensional sketch of the new conceptually digital camera is shown in Figure 4.

Step 4 (A-CSI evaluation and modification, product Assurance). After several times of modification based on the aesthetics consideration and human usage of hereafter possible 
TABLE 7: The design reference: the sample with high CSI score.

\begin{tabular}{|c|c|c|c|}
\hline \multicolumn{2}{|c|}{ Sample N15 } & \multicolumn{2}{|c|}{ Weightings } \\
\hline Design category & Design elements & $\operatorname{PCC}\left(Y_{1}\right)$ & $\operatorname{PCC}\left(Y_{3}\right)$ \\
\hline $\mathrm{X} 1$ & X11 & -0.140 & 0.471 \\
\hline $\mathrm{X} 2$ & $\mathrm{X} 23$ & 0.000 & 0.000 \\
\hline $\mathrm{X} 3$ & $\mathrm{X} 33$ & 1.092 & 0.940 \\
\hline $\mathrm{X} 4$ & $\mathrm{X} 42$ & 0.000 & 0.000 \\
\hline $\mathrm{X} 5$ & X51 & 0.000 & 0.000 \\
\hline X6 & X62 & 0.000 & 0.000 \\
\hline $\mathrm{X} 7$ & $\mathrm{X} 72$ & 0.109 & 0.061 \\
\hline $\mathrm{X} 8$ & $\mathrm{X} 81$ & 0.620 & -0.302 \\
\hline X9 & X91 & 0.262 & 0.286 \\
\hline X10 & X102 & 0.138 & 0.332 \\
\hline $\mathrm{X} 11$ & $\mathrm{X} 112$ & -0.084 & 0.445 \\
\hline \multicolumn{2}{|c|}{ Kansei word credits $\left(Y_{1}, Y_{2}, Y_{3}\right)$} & $Y_{1}=4.98$ & $Y_{3}=5.65$ \\
\hline
\end{tabular}

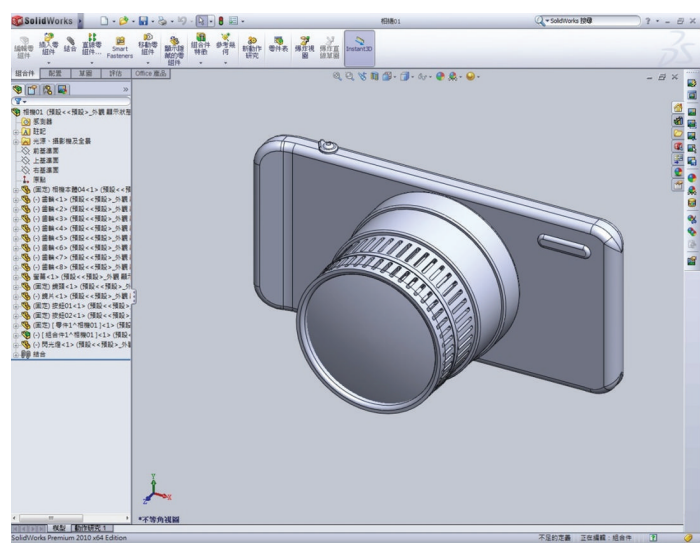

FIgURE 4: The prototype of a new design camera.

manufacturing process, the final model of a new digital camera is obtained, as shown in Figure 5.
TABLE 8: Verification of the new designed camera.

\begin{tabular}{lcccc}
\hline Product & $Y_{1}$ & $Y_{2}$ & $Y_{3}$ & CSI \\
\hline $\begin{array}{l}\text { Design } \\
\text { reference }\end{array}$ & $Y_{1}=4.98$ & $Y_{2}=4.9442$ & $Y_{3}=5.6548$ & 15.350 \\
$\begin{array}{l}\text { N15) } \\
\begin{array}{l}\text { New design } \\
\text { KKBDCA) }\end{array}\end{array}$ & $Y_{1}=6.222$ & $Y_{2}=5.511$ & $Y_{3}=5.756$ & 17.356 \\
Enhancement & $24.94 \%$ & $11.46 \%$ & $1.79 \%$ & $13.01 \%$ \\
\hline
\end{tabular}

3.5.2. Verification. To evaluate the design results through the operation of the proposed KKBDCA design scheme, an investigation is done to 30 subjects to evaluate the qualitysufficiency customers' preferences. The obtained results are shown in Table 8. Comparing the CSI value of new designed camera with the original sample (No. p15), it is found that a $13 \%$ increase in CSI is obtained. This reveals that a satisfying result is attended while using the proposed innovative KKBDCA product design procedure. 


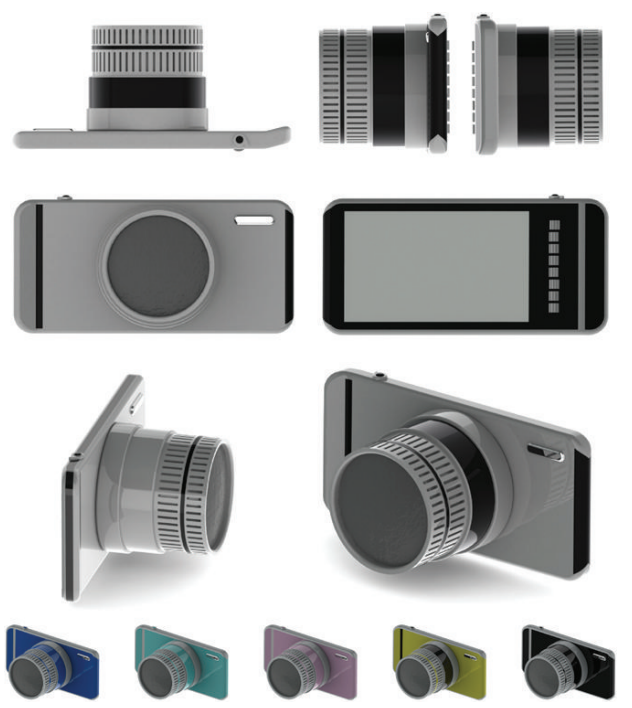

Figure 5: The final new designed product based on KKBDCA process.

\section{Conclusion}

This study aims to provide a design methodology to approach customer satisfaction more closely so as to rise up the possibility of customer's decision for buying the designed merchant. The proposed methodology, called KKBDCA, includes the modified Kano model, the Kansei engineering, the Quantum Theory I, and an innovative design procedure BDCA. A major conclusion is drawn as follows.

(1) Firstly, in the Kano model, the horizontal coordinate variables, that is, the quality factors, were modified as customer preferences (i.e., Kansei words). These influential quality factors were found as usability, aesthetics, and innovation. Then their weighting on customer satisfaction and Kano's classification were determined according to the questionnaire survey results.

(2) In Kansei manipulation, the target products, digital cameras, were collected and classified. Totally 60 effective samples were obtained and divided into 6 categories. Eleven design features of cameras were drawn from these sample representatives. According to the Kansei evaluation results of product design features with respect to each Kansei word for the 60 samples, the QT1 mapping model was built. Then a verification test was performed, and a good prediction result was obtained.

(3) In the last stage, an innovative product design procedure was proposed. Based on the viewpoints of lowweighting (including zero and negative weighting), design elements should be highly modified so as to more effectively and rapidly enhance customer satisfaction, and a brand new camera was thus designed. Meanwhile, to identify our proposed design procedure, a verification test for the overall customer satisfaction was done and a satisfying result was obtained.
The proposed integrated procedure not only extends the past Kansei evaluation results to really designing a new product but also provides a more effective approach to meet the customer satisfaction.

\section{References}

[1] M. Nagamachi, "Kansei engineering: a new ergonomic consumer-oriented technology for product development," International Journal of Industrial Ergonomics, vol. 15, no. 1, pp. 3-11, 1995.

[2] M. Nagamachi, Introduction of Kansei Engineering, Japan Standard Association, Tokyo, Japan, 1996.

[3] S. Ishihara, K. Ishihara, M. Nagamachi, and Y. Matsubara, "An automatic builder for a Kansei Engineering expert system using self-organizing neural networks," International Journal of Industrial Ergonomics, vol. 15, no. 1, pp. 13-24, 1995.

[4] S. S. Guan and Y. C. Lin, "A study on the color and style collocation of mobile phones using neural network method," Journal of Chinese Institute of Industrial Engineers, vol. 18, no. 6, pp. 84-94, 2001.

[5] B. B. Nadia, "Kansei mining: identifying visual impressions as patterns in images," in Proceedings of the International Conference IFSA/NAFIPS, Vancouver, Canda, 2001.

[6] K. C. Wang, "User-oriented product form design evaluation using integrated Kansei engineering scheme," Journal of Convergence Information Technology, vol. 6, no. 6, pp. 420-438, 2011.

[7] M. G. Helander and M. P. Tham, "Hedonomics-affective human factors design," Ergonomics, vol. 46, no. 13-14, pp. 12691272, 2003.

[8] S. Baek, M. Hwang, H. Chung, and P. Kim, "Kansei factor space classified by information for Kansei image modeling," Applied Mathematics and Computation, vol. 205, no. 2, pp. 874-882, 2008.

[9] H.-Y. Chen and Y.-M. Chang, "Extraction of product form features critical to determining consumers' perceptions of product image using a numerical definition-based systematic approach," International Journal of Industrial Ergonomics, vol. 39, no. 1, pp. 133-145, 2009.

[10] D. Clausing, Total Quality Development: A Step-by-Step Guide to World-Class Concurrent Engineering, ASME Press, New York, NY, USA, 1994.

[11] R. T. K. Fung and Popplewell, "The analysis of customer requirements for effective rationalization of product attributes in manufacturing," in Proceedings of the 3rd International Conference on Manufacturing Technology, pp. 287-296, Hong Kong, 1995.

[12] X. Chen, C. J. Barnes, T. H. C. Childs, B. Henson, and F. Shao, "Materials' tactile testing and characterisation for consumer products' affective packaging design," Materials and Design, vol. 30, no. 10, pp. 4299-4310, 2009.

[13] C.-C. Yang, "Constructing a hybrid Kansei engineering system based on multiple affective responses: application to product form design," Computers and Industrial Engineering, vol. 60, no. 4, pp. 760-768, 2011.

[14] M.-S. Huang, H.-C. Tsai, and T.-H. Huang, "Applying Kansei engineering to industrial machinery trade show booth design," International Journal of Industrial Ergonomics, vol. 41, no. 1, pp. 72-78, 2011.

[15] C.-C. Chen and M.-C. Chuang, "Integrating the Kano model into a robust design approach to enhance customer satisfaction 
with product design," International Journal of Production Economics, vol. 114, no. 2, pp. 667-681, 2008.

[16] C. E. Osgood, P. H. Tannenbaum, and G. J. Suci, The Measurement of Meaning, University of Illinois Press, Urbana, Ill, USA, 1957.

[17] J. B. Kruskal, "Multidimensional scaling by optimizing goodness of fit to a nonmetric hypothesis," Psychometrika, vol. 29, no. 1, pp. 1-27, 1964.

[18] N. Cross, Engineering Design Methods: Strategies for Product Design, John Wiley \& Sons, Chichester, UK, 2000. 


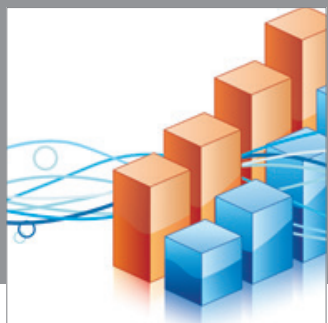

Advances in

Operations Research

mansans

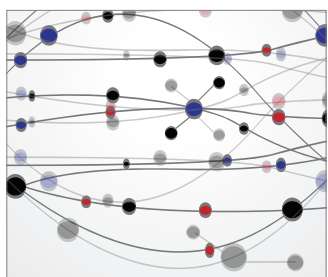

The Scientific World Journal
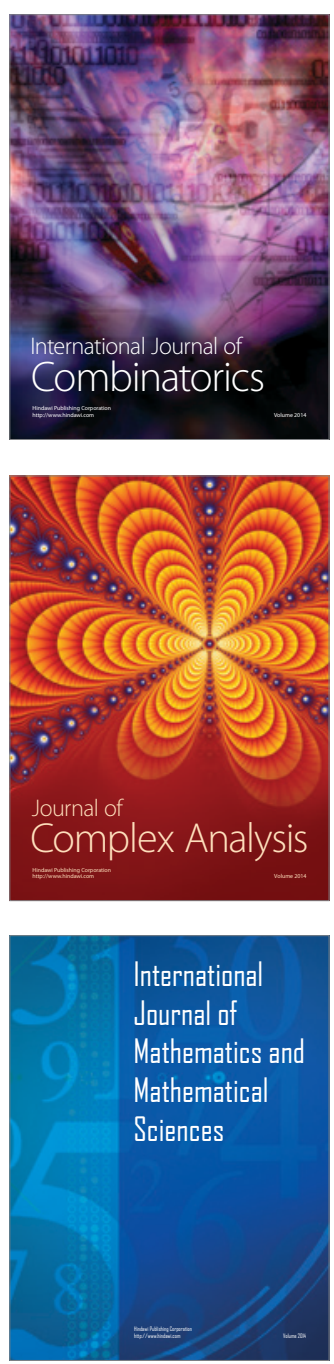
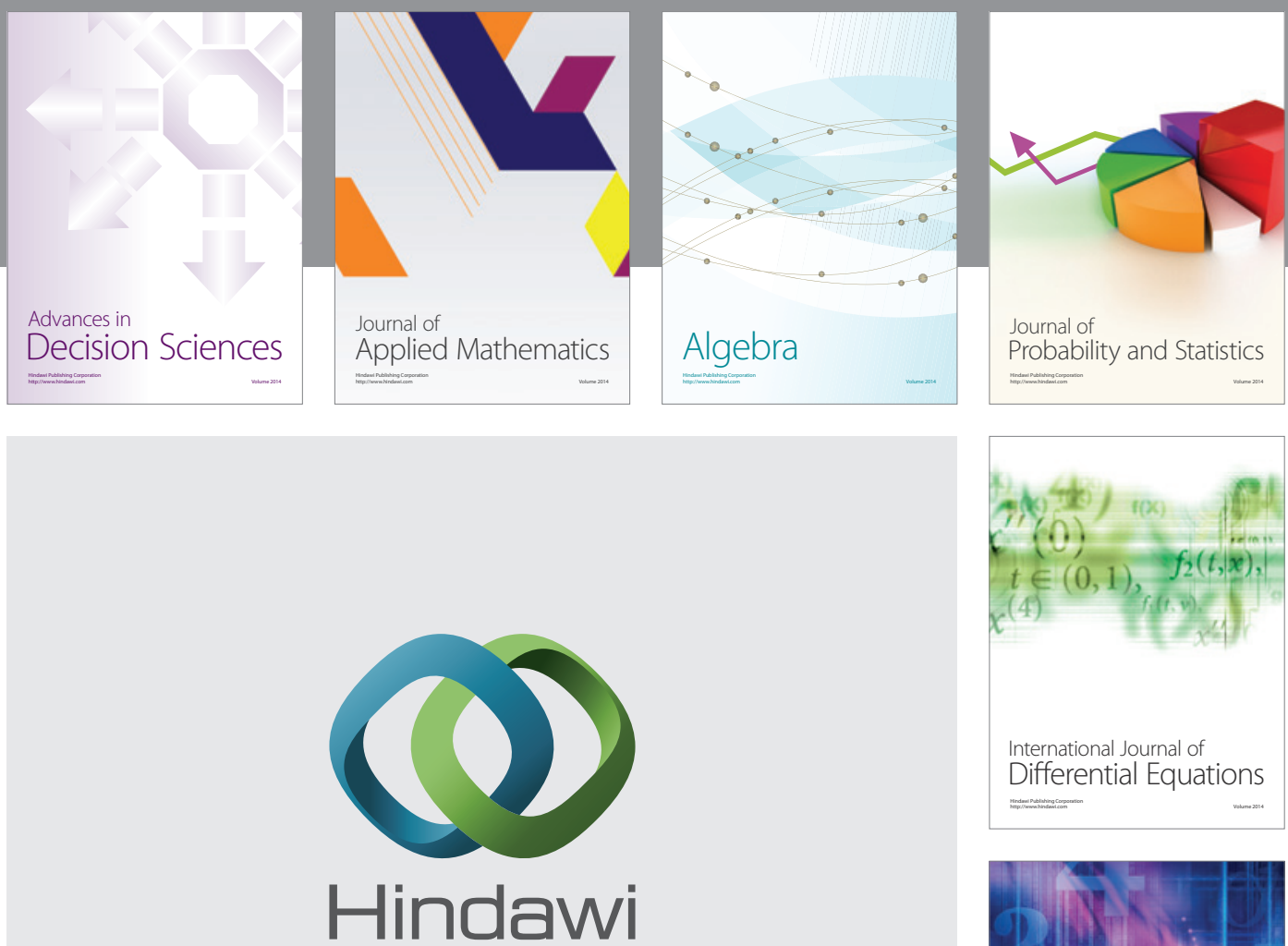

Submit your manuscripts at http://www.hindawi.com
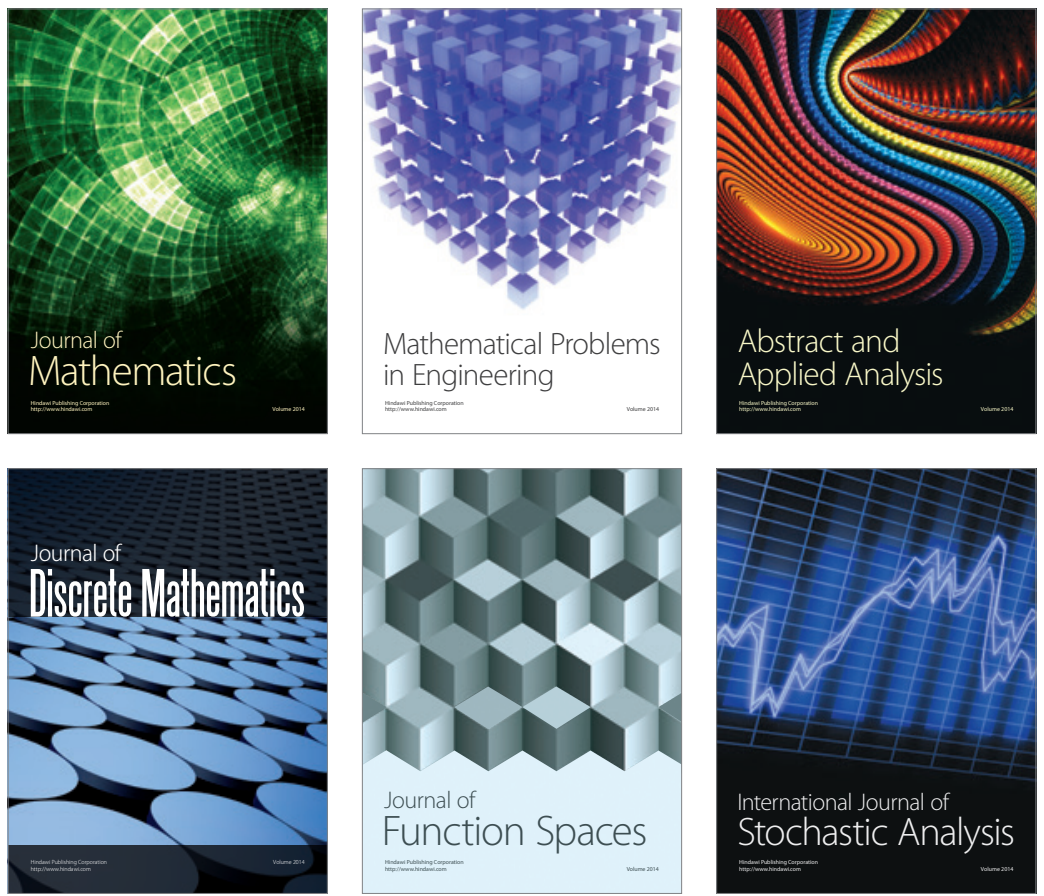

Journal of

Function Spaces

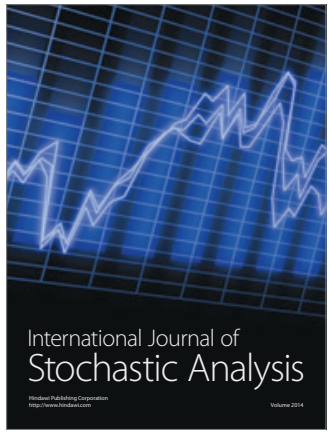

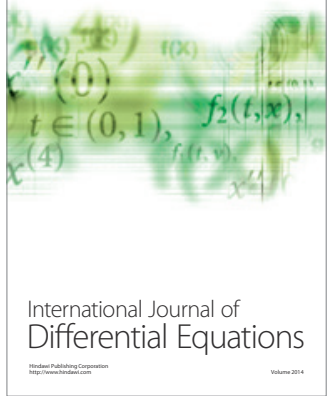
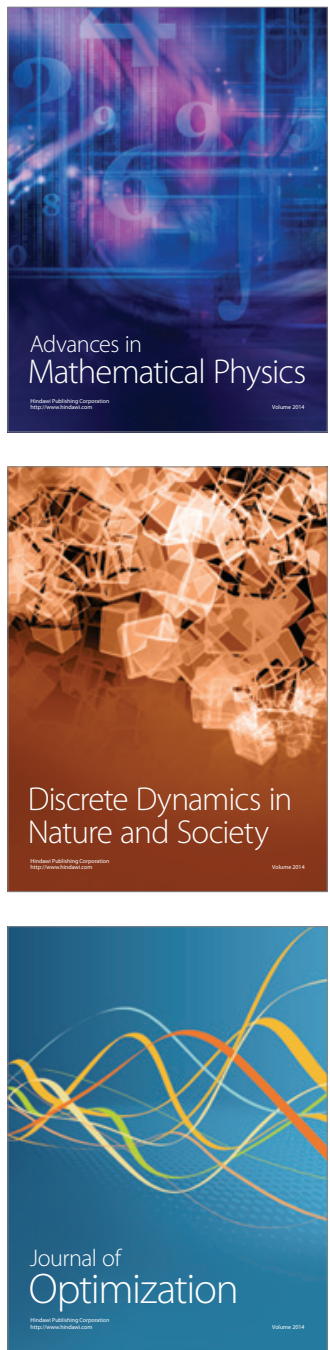